\title{
A Mineral Seed Coating for Control of Seedling Diseases of Alfalfa Suitable for Organic Production Systems
}

Deborah A. Samac, United States Department of Agriculture-Agricultural Research Service, Plant Science Research Unit, and Department of Plant Pathology, University of Minnesota, St. Paul 55108; Samuel Schraber, Department of Plant Pathology, University of Minnesota, St. Paul; and Stuart Barclay, Summit Seed Coatings, Caldwell, ID 83605

\begin{abstract}
Samac, D. A., Schraber, S., and Barclay, S. 2015. A mineral seed coating for control of seedling diseases of alfalfa suitable for organic production systems. Plant Dis. 99:614-620.

Most alfalfa seed is treated with the fungicide mefenoxam (Apron XL) for control of soilborne seedling diseases caused by Phytophthora medicaginis and Pythium spp. However, Apron XL is not active against Aphanomyces euteiches, the causal agent of Aphanomyces root rot (ARR), an important component of the alfalfa seedling root rot complex. Moreover, Apron XL-treated seed cannot be used in organic production systems. A seed coating using aluminosilicate (natural zeolite) at a rate of $0.33 \mathrm{~g}$ of zeolite per gram of alfalfa seed was tested as an alfalfa seed treatment. Inoculated growth chamber trials were conducted to determine the percentage of seedlings protected from Phytophthora root rot (PRR) and ARR. The mineral seed coating resulted in significantly greater control of PRR, with a mean of $89 \%$ healthy seedlings (disease score of 1 or 2 on a 1-to-5 scale) compared with the Apron XL treatment, with a mean of 38\% healthy seedlings, or the control treatment, with $15 \%$ healthy seedlings. The mineral

seed coating also resulted in significantly greater protection against ARR, with $67 \%$ healthy seedlings compared with 3 and $2 \%$ healthy seedlings with the Apron XL and control treatments, respectively. The coated seed were used for in vitro assays with Pythium ultimum and P. paroecandrum to test for protection from seed rot and damping off. The mineral seed coating resulted in a significantly greater percentage of healthy seedlings compared with the Apron XL and control treatments. In growth chamber assays with naturally infested field soils with a range of disease pressure, the mineral seed coating resulted in a similar or greater percentage of healthy plants than the Apron XL treatment. The mineral coating had no effect on in vitro growth of Sinorhizobium meliloti, and nodule numbers were similar on roots from mineral-coated and untreated seed. These experiments indicate that the zeolite seed coating is a promising means of controlling seedling diseases in alfalfa production systems.
\end{abstract}

Alfalfa (Medicago sativa L.) is a key feed and forage component in dairy cow, sheep, and beef production systems as dried hay, haylage, and for grazing. It provides a high concentration of crude protein as well as vitamins, minerals, and the dietary fiber needed to maintain rumen health. Moreover, alfalfa provides numerous ecological services that make it an important part of crop rotations, including providing all or most of the nitrogen $(\mathrm{N})$ for subsequent grain crops in a rotation due to its capacity for symbiotic nitrogen fixation, reducing soil erosion, promoting soil carbon sequestration, and breaking pest and pathogen cycles $(3,6,17,27,38)$.

However, establishing alfalfa can be challenging because alfalfa seed and seedlings are vulnerable to several soilborne pathogens that can reduce plant density and cause damage to root systems, which decreases plant productivity and reduces winter survival. The majority of alfalfa seed is treated commercially with the systemic fungicide mefenoxam, R,S-2-[(2,6-dimethylphenyl)-methoxyacetylamino]propionic acid methyl ester (Apron XL), to provide protection against Pythium seed rot and damping-off and Phytophthora root rot (PRR), as well as inoculated with Sinorhizobium meliloti to promote nodulation and biological nitrogen fixation. The United States Department of Agriculture National Organic Program standards permit use of microbial inoculants to seed as long as they are not genetically engineered but prohibit the use of chemical fungicides (http://www.ams.usda.gov/

Corresponding author: D. A. Samac; E-mail: debby.samac@ars.usda.gov

Mention of any trade names or commercial products in this article is solely for the purpose of providing specific information and does not imply recommendation or endorsement by the United States Department of Agriculture.

Accepted for publication 25 September 2014.

http://dx.doi.org/10.1094/PDIS-03-14-0240-RE

This article is in the public domain and not copyrightable. It may be freely reprinted with customary crediting of the source. The American Phytopathological Society, 2015.
AMSv1.0/nop). Currently, there are no commercial organic seed treatments that have been tested for protection of alfalfa seed against soilborne pathogens. Without an effective seed treatment, alfalfa is prone to high levels of disease and poor plant establishment in locations with soilborne pathogen pressure. For alfalfa, strong seedling establishment is particularly important to achieve the plant density needed to outcompete weeds and produce high biomass yields. Effective seed treatments that meet the organic standards are needed to expand production of organic alfalfa for support of organic dairy and animal production systems.

The soilborne complex causing damping-off and seedling root diseases of alfalfa includes Pythium spp., Phytophthora medicaginis E. M. Hansen \& D. P. Maxwell, Aphanomyces euteiches Drechsler, Rhizoctonia solani, and Fusarium spp. (13,31). Stand losses due to these pathogens can be substantial $(1,11,13,14,16,30,31,35,37)$. Resistance to PRR has been incorporated into the majority of modern alfalfa cultivars. Nonetheless, resistant cultivars were shown to benefit from fungicide seed treatment (30). Due to the obligate outcrossing nature of alfalfa, a cultivar is considered to have high resistance if more than $50 \%$ of the plants show a resistant phenotype in a standard test to characterize alfalfa cultivars (http://www.naaic.org/stdtests/ phytophtseeds.htm). Fungicide seed treatment likely provides protection to susceptible plants within a cultivar and augments genetic resistance under highly conducive disease conditions (30). Alfalfa cultivars vary in susceptibility to Pythium spp. (1) but cultivars are not routinely selected for resistance to Pythium seed rot and damping off. Apron XL seed treatment has been shown to be highly effective against many oomycete pathogens, including Pythium and Phytophthora spp. (22). However, Apron XL does not provide protection against Aphanomyces root rot (ARR; 35). Two races of A. euteiches causing ARR of alfalfa have been identified. Although many modern alfalfa cultivars have resistance to race 1 of $A$. euteiches, fewer have been developed with resistance to both race 1 and race 2 . Soils with race 2 are widely distributed in alfalfa-growing regions of the United States $(20,21,25)$, and strains that can overcome host resistance to race 1 and race 2 have been reported (21). Protection against ARR 
is becoming increasingly important in both organic and conventional agriculture.

Zeolites are crystalline hydrous aluminosilicate minerals found around the world in sedimentary deposits derived from volcanic materials. Because of their high cation-exchange capacity, zeolites are used in numerous industrial processes, in agriculture, and in environmental remediation (23). Broad antimicrobial properties have been demonstrated for synthetic zeolites ion exchanged with silver, copper, and zinc (7). Natural zeolites are used as conditioners to improve the chemical and physical properties of soil for plant growth. They are frequently used on golf courses to increase water infiltration, water-holding capacity, and aeration. Recently, natural zeolite was shown to have potential for reducing the symptoms from fairy ring fungi on a golf fairway (10), suggesting that natural zeolites may have antifungal activity.

The objective of this study was to evaluate the effectiveness of natural zeolite as a seed coating to protect seedlings from PRR, ARR, and seed rot and damping-off by Pythium spp. in inoculated growth chamber experiments and from the soilborne pathogen complex in naturally infested soils under controlled conditions. We found that the zeolite seed coating provided protection that was equal to or superior to that provided by the Apron XL seed treatment against Pythium spp. and PRR, it provided strong protection against ARR, and it did not interfere with growth of $S$. meliloti or inhibit development of root nodules.

\section{Materials and Methods}

Seed and pathogen inoculum preparation. Alfalfa seed with three different seed coatings were obtained from Summit Seed Coatings (Caldwell, ID): a control with no fungicide, Apron XL treated, and zeolite coating. All seed coatings were applied using a commercial rotostat seed-coating machine in which seed circulate along the walls of a vertical cylinder, atomized adhesive is applied, and then fungicides, inoculant, and calcium carbonate (limestone) are applied. The coating is packed onto the seed as they circulate in the cylinder. The coated seed are then dried and screened. For these experiments, the control coating consisted of calcium carbonate at $0.34 \mathrm{~g} / \mathrm{g}$ of alfalfa seed without inoculant or fungicide. The Apron XL treatment consisted of 0.64 fluid ounces of Apron XL per 100 pounds of seed ( $18.9 \mathrm{ml}$ per $45.4 \mathrm{~kg}$ of seed) and calcium carbonate at $0.34 \mathrm{~g} / \mathrm{g}$ of seed without inoculant. The zeolite treatment consisted of powdered zeolite at $0.34 \mathrm{~g} / \mathrm{g}$ of seed as a seed coating without calcium carbonate or inoculant.

For the PRR assay, P. medicaginis strain A2A1 was grown on V8 juice agar in $90-\mathrm{mm}$-diameter petri plates at room temperature for 7 days. The culture was homogenized for $1 \mathrm{~min}$ in $250 \mathrm{ml}$ of sterile distilled water in a blender to comminute the mycelium and then diluted to a final volume of $1,000 \mathrm{ml}$. For the ARR assay, A. euteiches strain MF-1 (race 1) or WAS-W5-2, that overcomes host resistance to race 1 and race 2, was used. Strain WAS-W5-2 was isolated from a diseased alfalfa seedling grown in soil from Waseca, $\mathrm{MN}$ in 2013. Cultures were grown on corn meal agar (CMA; Becton, Dickinson and Company, Sparks, MD) in 90-mm-diameter petri plates for 7 days at room temperature. The cultures were homogenized for $1 \mathrm{~min}$ in $250 \mathrm{ml}$ of sterile distilled water in a blender to comminute the mycelium and then diluted to a final volume of $1,000 \mathrm{ml}$ with sterile distilled water. For experiments in which both $P$. medicaginis and $A$. euteiches were applied to plants, the inoculum was prepared by homogenizing half of a culture plate of each pathogen together in $250 \mathrm{ml}$ of sterile distilled water and then diluted to $1,000 \mathrm{ml}$. For the Pythium seed rot and damping-off assay, Pythium ultimum Trow strains GR1 and W3 and P. paroecandrum Drechsler strain L3 (1) were grown on CMA plates for 4 days at room temperature. For each strain, a 5-mm-diameter plug of mycelium from the culture margin was transferred to $1.5 \%$ water agar in a $90-\mathrm{mm}$-diameter petri plate and cultured at room temperature for 3 days.

PRR assay. The assay was similar to the standard test used to evaluate resistance in alfalfa cultivars (http://www.naaic.org/stdtests/ phytophtseeds.htm). Briefly, horticultural tray inserts $(5.7$ by $5.7 \mathrm{~cm}$, Standard Insert 2401; T. O. Plastics, Clearwater, MN) were filled with $80 \mathrm{~cm}^{3}$ of medium-grade vermiculite (Sungro, Bellevue, WA), planted with 25 coated alfalfa seeds, covered with $15 \mathrm{~cm}^{3}$ of Sunshine Professional Growing Mix (Sungro), and watered sufficiently to wet the vermiculite. Flats were placed in a growth chamber with a temperature regime of 24 and $19^{\circ} \mathrm{C}$ day and night, respectively, and a 16-h photoperiod. Flats were watered daily for 7 days to maintain moist vermiculite. At 7 days after planting (dap), when plants had developed the unifoliate leaf, each insert was inoculated by pipetting $25 \mathrm{ml}$ of comminuted mycelium, prepared as described above, onto the surface of the Sunshine Mix around the hypocotyls of the seedlings. Water was added to the surrounding reservoir immediately after inoculation to saturate the entire root zone. Plants were held in flooded conditions for 2 days, then watered daily to maintain moist vermiculite. Plants were fertilized with Peters 10:10:10 fertilizer (Scotts-Sierra Horticultural Products Co., Marysville, $\mathrm{OH}$ ) at 14 dap. Initial experiments tested the effect of inoculum concentration by diluting the inoculum $1: 1$ $(0.5 \times)$ or $1: 3(0.25 \times)$ with sterile distilled water. Subsequent experiments were conducted with the $1 \times$ inoculum concentration. There were four to six replications for each seed-coating treatment using 25 seeds/ replication, and the assay was done three times. Experiments using a mixture of Phytophthora medicaginis and A. euteiches as the inoculum were conducted in the same manner. Plants were removed from the vermiculite at 21 dap and rated for disease symptoms on a 1-to-5 scale, in which $1=$ no necrosis of roots or hypocotyls; 2 = slight necrosis of roots and hypocotyls; $3=$ necrosis of roots and lower hypocotyl, moderate stunting of stem; 4 = extensive necrosis of roots and hypocotyl, severe stunting; and $5=$ lack of root system, dead seedling. A rating of 1 or 2 was considered to be healthy and protected from disease. Plants were dried at $37^{\circ} \mathrm{C}$ for 3 days and then weighed to determine dry weight.

ARR assay. The assay was done using the same protocol as the PRR assay, except that plants were flooded for 5 days immediately after inoculation. The inoculum consisted of $25 \mathrm{ml}$ of comminuted mycelium of A. euteiches, prepared as described above, that was pipetted onto the surface of the Sunshine Mix around the hypocotyls of the seedlings. Initial experiments tested the effect of inoculum concentration by diluting the inoculum $1: 1(0.5 \times)$ or $1: 3(0.25 \times)$ with sterile distilled water. Subsequent experiments were conducted with the $1 \times$ inoculum concentration. There were four to six replications for each seed-coating treatment using 25 seeds/replication and the assay was done three times. The same scale was used for rating disease as for the PRR assay.

Pythium seed rot and damping-off assay. The assay was similar to that used to evaluate resistance in alfalfa cultivars (http://www. naaic.org/stdtests/pythium.htm). Briefly, 25 coated alfalfa seeds were placed on a $1.5 \%$ water agar plate, previously inoculated as described above with either Pythium ultimum GR1, P. ultimum W3, or $P$. paroecandrum L3. There were four replicate plates of each pathogen with each seed-coating treatment using 25 seeds/plate. Plates were placed in a lighted growth chamber at $19^{\circ} \mathrm{C}$ with a 16 -h photoperiod. Seedlings were evaluated for disease symptoms at 5 days after plating on a 1 -to- 5 scale, with $1=$ healthy seedling, primary root free of necrosis; $2=$ infected seedling, primary root tip necrotic but firm; 3 = infected seedling, primary root tip soft and rotted; $4=$ dead seedling, germinated seed with rotted radicle; and $5=$ dead seed, ungerminated rotted seed. A score of 1 or 2 was considered to be healthy and protected from disease. The experiment was done two times.

Nodulation and $S$. meliloti growth inhibition assay. Coated seed were planted in vermiculite as described above for the PRR assay. S. meliloti strain 102F51 was cultured for 3 days on Difco R2A agar medium (Becton, Dickinson and Company) and then a suspension of cells was made in sterile water with a concentration at an optical density at $600 \mathrm{~nm}\left(\mathrm{OD}_{600}\right)=0.1$ (approximately $\left.5 \times 10^{8} \mathrm{CFU} / \mathrm{ml}\right)$. Seed in each insert were inoculated by pipetting $1 \mathrm{ml}$ of the bacterial suspension onto seed and then the seed were covered with $15 \mathrm{~cm}^{3}$ of Sunshine potting mix. Plants were fertilized with half-strength Hoagland's solution without nitrogen every other day. At 21 dap, nodule numbers on each plant were counted. There were four replications for each seed-coating treatment, with 25 seeds/replication. The experiment was done two times.

An in vitro assay was conducted to test for inhibition of growth of S. meliloti by the Apron XL and mineral seed-coating treatments. 
S. meliloti 102F51 cells were suspended in sterile distilled water $\left(\mathrm{OD}_{600}=0.2\right)$ and $100 \mu \mathrm{l}$ was spread on $1.5 \%$ water agar or $\mathrm{R} 2 \mathrm{~A}$ plates. After the inoculum had dried, 15 coated alfalfa seeds were placed on each plate. Duplicate plates were made for each seedcoating treatment. Plates were incubated at room temperature for 5 days, then observed for the presence of clear zones around coated seed indicating bacterial growth inhibition.

Soil assay. This assay was conducted to investigate whether the seed-coating treatments would protect alfalfa seedlings from the complex of pathogens causing seedling root rot diseases in naturally infested soil in controlled conditions. Field soil was collected from 12 alfalfa fields in Minnesota in which alfalfa had been grown for at least three production years. Soil was placed in a cooler for transport to the lab and held at $4{ }^{\circ} \mathrm{C}$ until used in the assay. The locations were

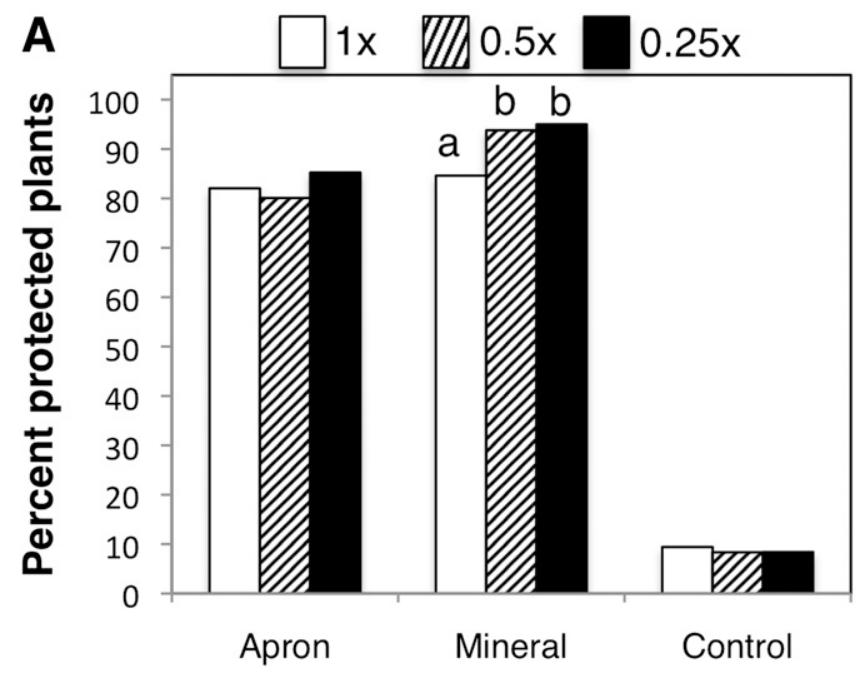

Seed coating treatment

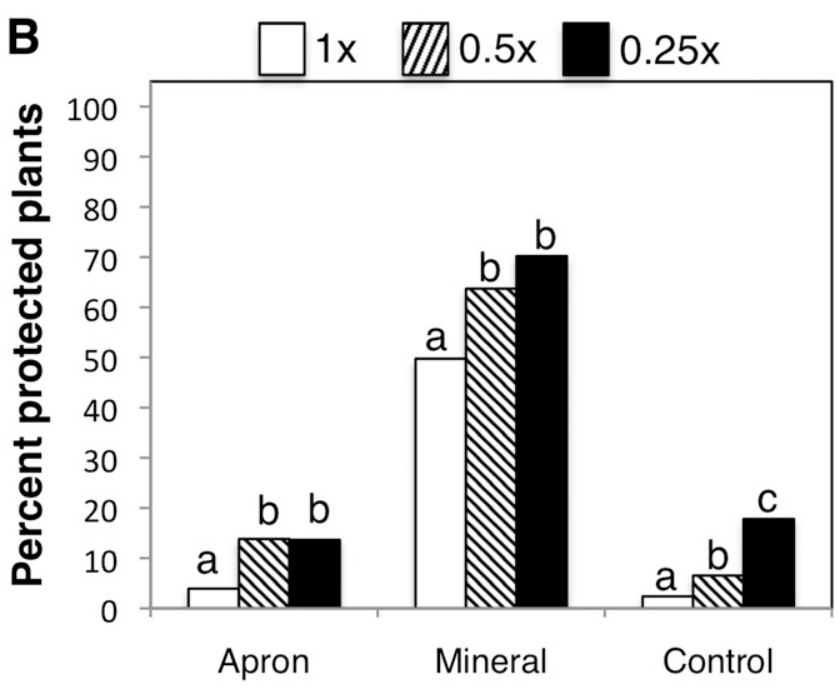

\section{Seed coating treatment}

Fig. 1. Effect of inoculum dose on Phytophthora root rot (PRR) and Aphanomyces root rot (ARR) symptoms. The $1 \times$ inoculum concentration was prepared by homogenizing a 7-day-old culture plate of Phytophthora medicaginis or Aphanomyces euteiches in a total of 1 liter of sterile distilled water. Seed were treated with mefenoxam (Apron $\mathrm{XL}$ ), natural zeolite (mineral), or had no treatment (control). Plants were inoculated at 7 days after planting and flooded for 2 days (PRR) or 5 days (ARR). Plants were scored for disease symptoms on a 1-to- 5 scale at 21 days after planting. Plants with a score of 1 or 2 were considered protected from disease. Columns marked with a different letter within a seed treatment group were significantly different at $P \leq 0.05$. A, Average percent protected plants after inoculation with $P$. medicaginis. B, Average percent protected plants after inoculation with $A$. euteiches.
Becker, Brewster, Elmore, Fulda, Hutchinson, Parkers Prairie, Rochester, Rosemount, St. Cloud, St. Hilaire, and two different fields in Waseca. Soil was sieved to remove rocks and plant debris, mixed thoroughly, and $80 \mathrm{~cm}^{3}$ was placed in plastic tray inserts $(5.7$ by $5.7 \mathrm{~cm}$ ). Each insert was planted with 25 coated seeds that were then covered with an additional $15 \mathrm{~cm}^{3}$ of field soil and watered to moisten soil. Flats were placed in a growth chamber at temperatures of 24 and $19^{\circ} \mathrm{C}$, day and night, respectively, with a 16-h photoperiod, and watered daily. At 7 dap, water was added to the surrounding reservoir in order to saturate the entire root zone. After 3 days, trays were drained and plants were watered as needed thereafter to
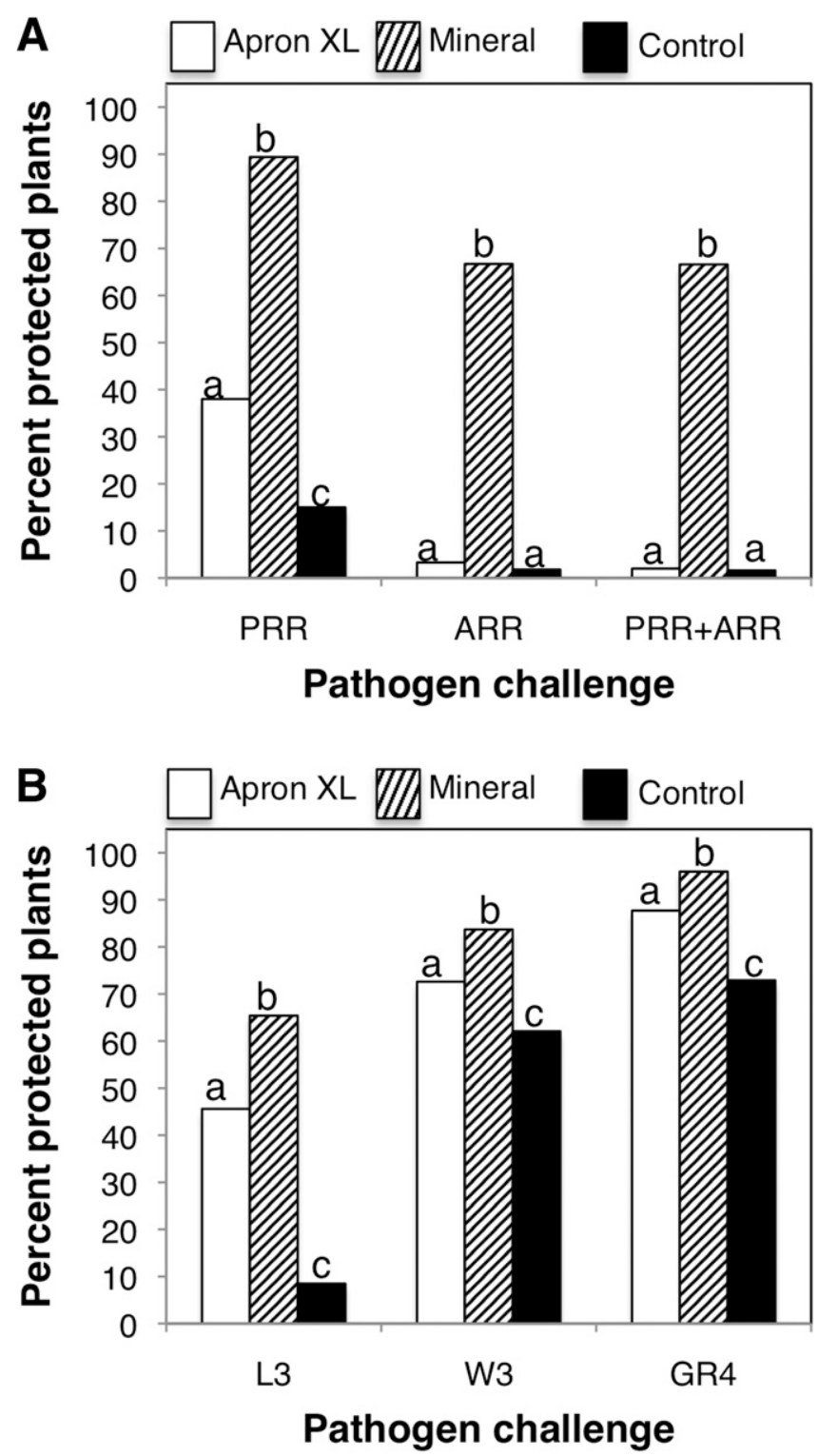

Fig. 2. Effect of seed treatment on symptoms of Phytophthora root rot (PRR), Aphanomyces root rot (ARR), and Pythium seed rot and damping-off. A, The inoculum was prepared by homogenizing a 7-day-old culture plate of Phytophthora medicaginis or Aphanomyces euteiches in a total of 1 liter of sterile distilled water. The PRR + ARR inoculum used equal amounts of each pathogen. Seed were treated with mefenoxam (Apron $\mathrm{XL}$ ), natural zeolite (mineral), or had no treatment (control). Plants were inoculated at 7 days after planting and flooded for 2 days (PRR and PRR + ARR) or 5 days (ARR). Plants were scored for disease symptoms on a 1-to- 5 scale at 21 days after planting. Plants with a score of 1 or 2 were considered protected from disease. B. Treated seed were germinated on $1.5 \%$ water agar plates previously inoculated with Pythium ultimum strains GR1 and W3 and $P$. paroecandrum strain $L 3$, grown in a lighted growth chamber at $19^{\circ} \mathrm{C}$ for 5 days, and then scored on a 1-to- 5 scale for disease symptoms. Plants with a score of 1 or 2 were considered protected from disease. Columns marked with a different letter within a pathogen challenge group were significantly different at $P \leq 0.05$. 
maintain moist soil conditions. At 21 dap, plants were removed from soil and scored for disease symptoms as described for the PRR assay. There were six replications for each seed coat treatment using 25 seeds/replication and the assay was done two times. From each soil, six diseased plants from the control treatment were used for total DNA extraction using the FastDNA Kit (MP Biomedicals, Solon, $\mathrm{OH}$ ) and tested in polymerase chain reaction (PCR)-based assays to detect Phytophthora medicaginis and A. euteiches DNA $(33,34)$.

Data analysis. One-way analysis of variance (ANOVA) was performed on transformed data (arcsine square root of the proportion of protected plants) and, if $P$ values indicated a significant difference $(P \leq 0.05)$, means were separated with the Tukey-Kramer Multiple Comparisons test using Instat (GraphPad Software, Inc., San Diego, CA). ANOVA and the Tukey-Kramer Multiple Comparisons test was also performed on plant dry weight measurements and plant nodule number.

\section{Results}

Effect of the inoculum concentration and seed-coating treatments in the PRR and ARR assays. The effect of inoculum concentration on disease symptoms was tested using three inoculum concentrations. Inoculum concentration of $P$. medicaginis had no significant effect on plants with the Apron XL and control seedcoating treatment (Fig. 1A). The average percentage of protected plants was similar for the $1 \times, 0.5 \times$, and $0.25 \times$ inoculum concentrations. Plants from the mineral-coated seed showed a dose response with fewer protected plants at the highest inoculum dose. Three additional experiments were conducted using the $1 \times$ inoculum dose and the results combined. The mineral seed-coating treatment resulted in a significantly greater percentage of protected plants compared with the Apron XL and control coating treatments (Fig. 2A). The majority of plants from the mineral-coating treatment had no symptoms or mild root rot symptoms as a result of inoculation compared with the control coating treatment, in which plants had rotted hypocotyls and tap roots, lacked lateral roots, and had yellow stunted foliage (Fig. 3). Plants from the Apron XL and mineral seed-coating treatments had significantly greater dry weights compared with plants from the control coating treatment (Table 1). Interestingly, mockinoculated plants from the mineral-coated seed had greater dry weights compared with plants from the Apron XL and control coating treatments.

The A. euteiches inoculum concentration had a significant effect on plants regardless of the seed-coating treatment. The $1 \times$ inoculum dose resulted in a lower percentage of protected plants compared with the $0.5 \times$ and $0.25 \times$ concentrations for the Apron XL, mineral, and control coating treatments (Fig. 1B). Three additional experiments were conducted with the $1 \times$ inoculum dose using strain MF-1 and the results combined. The mineral-coating treatment significantly increased the percentage of protected plants compared with the Apron XL and control coating treatments, and increased dry weight of plants (Fig. 2A; Table 1). The mineral-coating treatment also protected plants from damage by strain WAS-W5-2 (Fig. 3), a strain that overcomes host resistance to race 1 and race 2. Plants from the mineral-coating treatment had few to no symptoms of ARR while plants from the Apron XL and control coating treatments had rotted roots and hypocotyls as well as yellow, stunted foliage.

Three experiments were done with a mixed inoculum of $P$. medicaginis and A. euteiches MF-1 and the results combined. The percentage of protected plants was similar for the mixed inoculum and
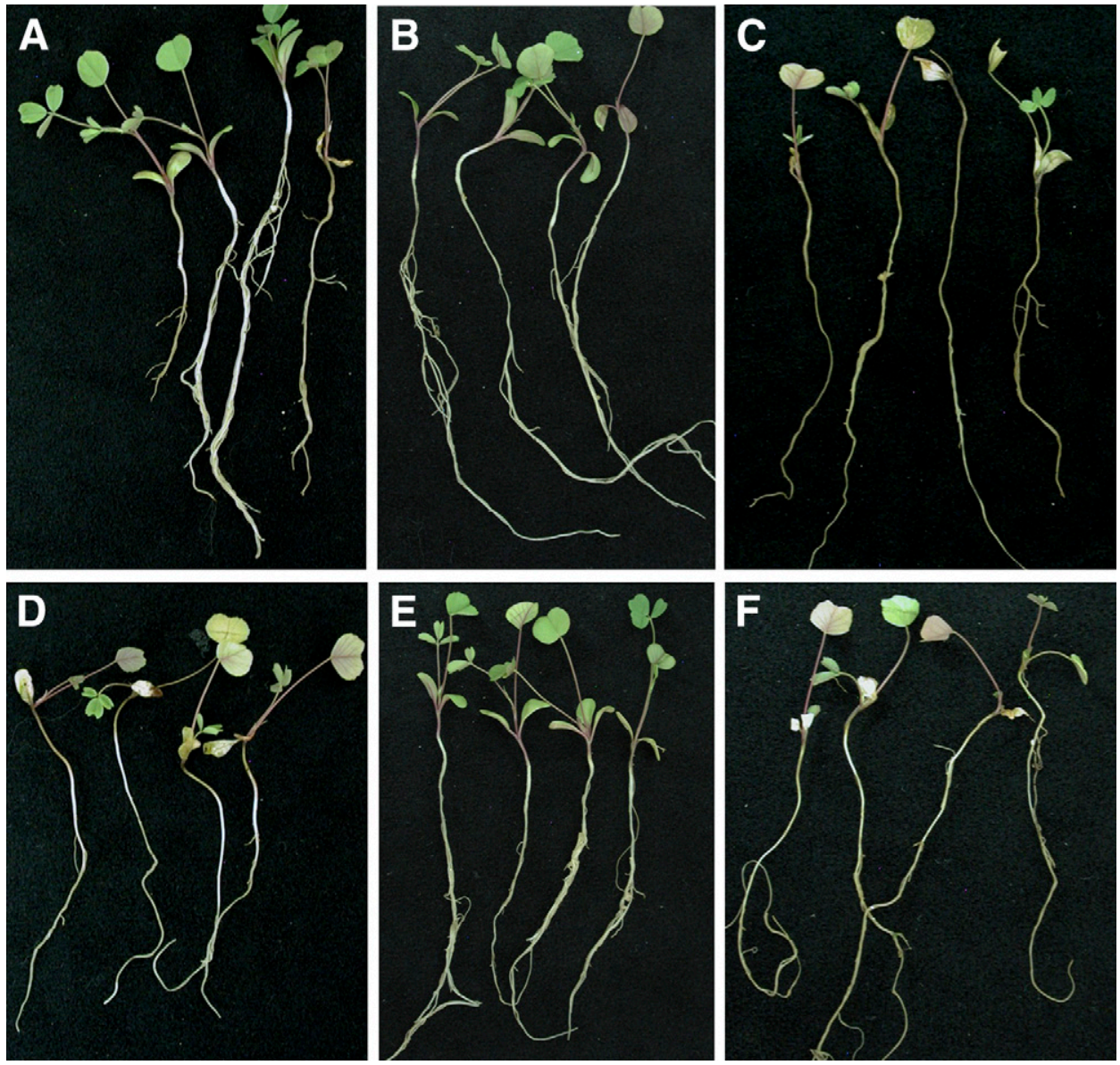

Fig. 3. Symptoms of Phytophthora root rot (PRR) and Aphanomyces root rot (ARR) at 21 days after planting. The Aphanomyces euteiches strain used overcomes host resistance to ARR. A, PRR with Apron XL seed treatment. B, PRR with mineral seed treatment. C, PRR with control seed treatment. D, ARR with Apron XL seed treatment. E, ARR with mineral seed treatment. F, ARR with control seed treatment. 
for the inoculum with A. euteiches alone. The mineral-coating treatment provided the highest level of control, with an average of $67 \%$ protected plants (Fig. 2A).

Pathogenicity of Pythium spp. and effect of seed-coating treatments on Pythium seed rot and damping-off. Three strains (Pythium ultimum W3, P. ultimum GR4, and P. paroecandrum L3) previously shown to be pathogenic on alfalfa (1) were used to challenge coated alfalfa seed in an in vitro plate assay. The experiment was done two times and the results combined. Strain L3 caused the most damage, with only $8.5 \%$ of the control coated seed without disease symptoms, while the $P$. ultimum strains caused less damage (Fig. 2B). The Apron XL and mineral seed-coating treatments were effective in protecting seed and seedlings from seed rot and damping-off. However, the mineral-coating treatment consistently had a significantly greater percentage of protected plants than the Apron XL treatment.

Effect of seed treatments on $\mathbf{S}$. meliloti and plant nodulation. An in vitro plate assay was used to test whether the seed-coating treatments inhibited growth of $S$. meliloti. No zones of bacterial growth inhibition were observed for any of the seed-coat treatments when seed were placed on plates spread with bacteria on $1.5 \%$ water agar or R2A agar. There were no significant differences in nodule numbers on plants between the control and mineral seed-coating treatments when seed were inoculated with a liquid suspension of S. meliloti at the time of planting, although nodule number on plants from Apron XL-treated seed was significantly lower than nodule number on plants from the control treatment (Table 1).

Table 1. Effect of seed treatments on plant dry weight from Phytophthora root rot (PRR) and Aphanomyces root rot (ARR) assays and nodule number after inoculation with Sinorhizobium meliloti at the time of planting

\begin{tabular}{lcccc}
\hline & \multicolumn{3}{c}{ Dry weight (mg/plant) } & \\
\cline { 2 - 4 } & PRR & ARR & $\begin{array}{c}\text { Mock } \\
\text { inoculated }\end{array}$ & $\begin{array}{c}\text { Average nodule } \\
\text { number/plant }\end{array}$ \\
\hline Apron XL & $7.6 \mathrm{a}$ & $6.1 \mathrm{a}$ & $8.4 \mathrm{a}$ & $6.5 \mathrm{a}$ \\
Mineral & $7.7 \mathrm{a}$ & $7.3 \mathrm{~b}$ & $10.7 \mathrm{~b}$ & $8.2 \mathrm{~b}$ \\
Untreated Control & $6.0 \mathrm{~b}$ & $6.0 \mathrm{a}$ & $8.2 \mathrm{a}$ & $8.3 \mathrm{~b}$ \\
\hline
\end{tabular}

${ }^{\mathrm{z}}$ Data represent means of two experiments with four replicates each. Means within a column followed by a different letter are significantly different $(P \leq$ $0.05)$.
Effectiveness of seed treatments for control of seedling root rot in naturally infested soil. Field soil from 12 fields was planted with coated seed and the soil was saturated for 3 days to promote root rot diseases. A wide range in severity of disease symptoms was observed, depending on the soil sample. However, there was evidence for the presence of both Phytophthora medicaginis and A. euteiches in all soil samples. Plants with root rot disease symptoms were positive for both pathogens by PCR-based assays (data not shown), indicating that both pathogens were present in the soils and causing disease. In soil samples from Becker, Fulda, and Parkers Prairie, all plants were scored as diseased $(0 \%$ protected plants) regardless of seed treatment, suggesting that these soils had very high populations of root rot pathogens or pathogens not sensitive to the seedcoating treatments. Soil from Hutchinson, Rosemount (ROS), St. Hilaire, and one Waseca site (WAS1) also appeared to have high populations of root rot pathogens because less than $10 \%$ of control coated seed were scored as protected (Fig. 4). In contrast, soils from Brewster, Rochester, St. Cloud (STC), and the second Waseca site appeared to have relatively low populations of root rot pathogens. Seed with no protection (controls) in these soils had greater than $66 \%$ plants scored as "protected", with mild symptoms or no symptoms of root rot. The percentage of protected plants in the STC soil sample was similar for all seed coat treatments, suggesting that the root rot observed was caused by a pathogen that was not controlled by Apron XL or the mineral coating. In eight soil samples, the Apron XL or mineral-coating treatment significantly increased the percentage of protected plants compared with the control treatment. In five soils, the mineral seed treatment resulted in a significantly greater percentage of protected plants than the Apron XL seed-coating treatment. In four soils, the mineral seed treatment protected more than $90 \%$ of the plants. The large difference in the percentage of protected plants between the Apron XL-treated and mineral-coated seed in the ROS and WAS1 soils suggests a high population density of $A$. euteiches or another pathogen not controlled by Apron XL.

\section{Discussion}

Results of growth chamber assays in which $P$. medicaginis, A. euteiches, and Pythium spp. were used as inoculum and growth chamber assays using naturally infested field soil showed that the mineral seed coating was as effective, or had greater protective

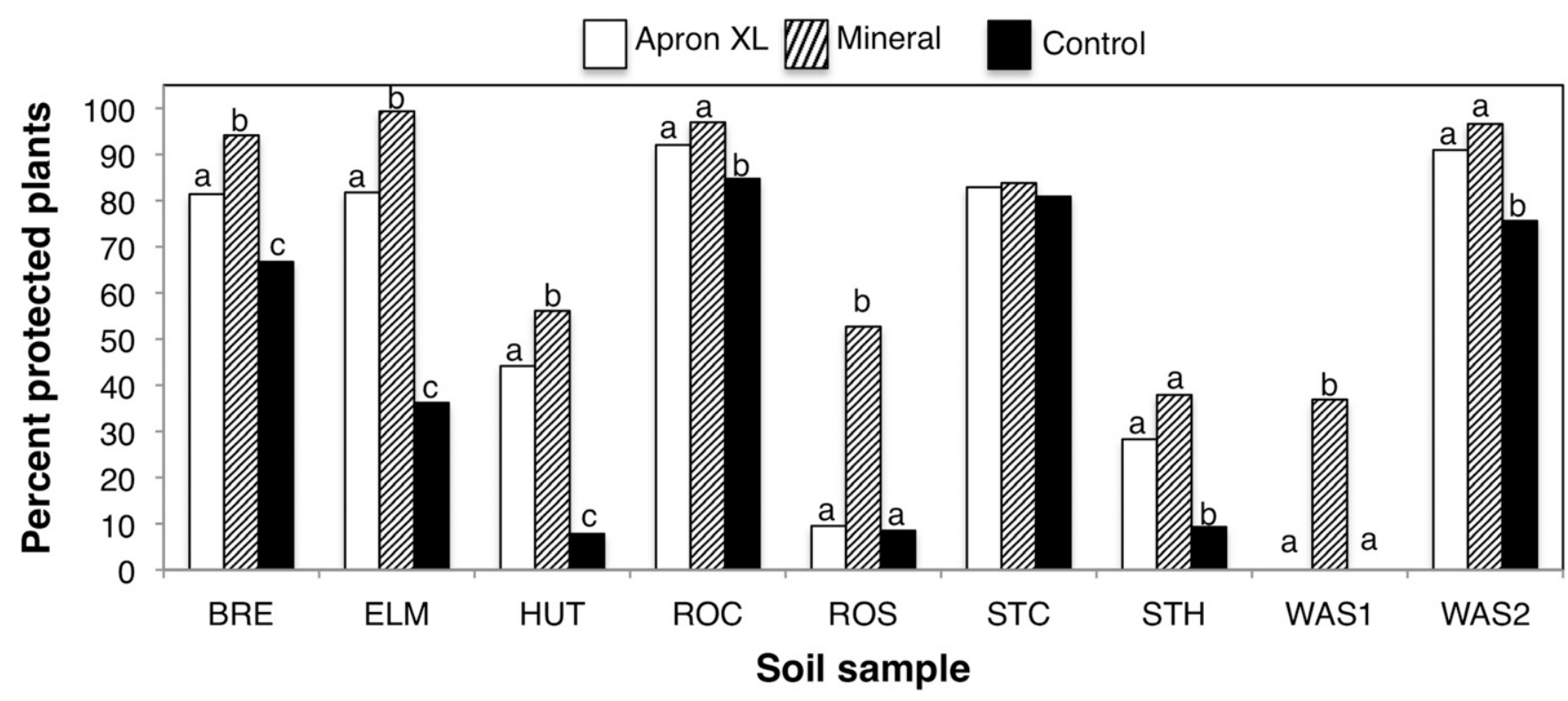

Fig. 4. Effectiveness of seed treatments in naturally infested soil. Soil was obtained from alfalfa fields in Minnesota. Seed were treated with mefenoxam (Apron XL), natural zeolite (mineral), or had no treatment (control). Treated seed were planted in soil after sieving and thorough mixing. Soil was flooded at 7 days after planting for 3 days and then watered as needed. Plants were evaluated for root rot symptoms on a 1-to-5 scale at 21 days after planting. Plants with a score of 1 or 2 were considered protected from disease. Columns marked with a different letter within a soil sample were significantly different at $P \leq 0.05$. Locations from which soil was obtained: BRE $=$ Brewster, ELM $=$ Elmore, HUT $=$ Hutchinson, ROC $=$ Rochester, ROS $=$ Rosemount, STC $=$ St. Cloud, STH $=$ St. Hilaire, UND = Underwood, and WAS = Waseca. 
activity, than the Apron XL seed-coating treatment. There was no evidence for a negative effect of the mineral coating on in vitro growth of $S$. meliloti or on root nodulation. Interestingly, the Apron XL treatment reduced nodule number compared with the mineral and control coating treatments. Several previous studies reported that metalaxyl (Apron) reduces the numbers of rhizobia on legume seed $(19,28)$ and a few studies found a reduction in nodule number (29). Metalaxyl was not found to reduce nitrogen fixation in alfalfa 5 weeks after planting using a commercial mixture of $S$. meliloti strains (8). It is possible that the $S$. meliloti strain 102F51 used in this study is more sensitive than strains in commercial inoculants. Although the efficacy of the mineral seed coating remains to be tested in field situations, the results of the controlled environmental assays indicate that it has promise as a seed treatment for control of soilborne diseases of alfalfa in conventional and organic production systems. The mineral seed coating would be advantageous in conventional agriculture due to its activity against ARR. At present, no chemical seed treatment is labeled for control of ARR on alfalfa. Additionally, tolerance of Pythium spp. and P. medicaginis to metalaxyl, a compound with the same mode of action as mefenoxam, has been reported $(5,15,24)$. Utilization of an alternative control strategy would help to reduce selection for mefenoxam-tolerant pathogens.

Organic production standards allow for the use of microbial inoculants for disease control. However, there are few reports of effective biological control treatments for seedling diseases of alfalfa. Treatment of alfalfa seed with strains of Bacillus cereus was shown to control seedling diseases, increase number of emerged seedlings, and increase forage yield in a range of field settings (18). Control of seedling disease by the bacterial inoculant was similar to the Aprontreated control, suggesting that the inoculant and Apron controlled similar pathogens, most likely P. medicaginis and Pythium spp. Although many microbial seed treatments have been commercialized for control of soilborne pathogens, to control the alfalfa seedling root disease complex, the treatment needs to be effective against diverse soilborne pathogens. Few organic seed treatments have been shown to have activity against multiple soilborne pathogens. A greenhouse study was conducted to evaluate 14 seed and drench treatments for organic management of three soilborne pathogens of spinach: Pythium ultimum, $R$. solani, and Fusarium oxysporum f. sp. spinaciae (4). None of the treatments tested were effective against all pathogens. Seed treatments with GTG I (a proprietary organic treatment), Natural II and Natural X (Actinomycete products), and Subtilex Biological fungicide (B. subtilis) reduced damping off by $P$. ultimum while GTG I and Natural II reduced damping off from $R$. solani. A drench treatment with Prestop Biofungicide (Gliocladium catenulatum) suppressed postemergence wilt by $F$. oxysporum f. sp. spinacieae. In our experiments, the mineral seed-coating treatment was highly effective against five important oomycete pathogens of alfalfa, including a strain of $A$. euteiches that overcomes ARR resistance in current alfalfa cultivars. Although activity against $R$. solani and Fusarium spp. was not tested specifically, the results of the soil assay indicate that the mineral seed coating is an effective means of protecting alfalfa seed and seedlings against multiple pathogens in the root rot complex under conditions conducive to disease.

The mechanism by which the mineral seed-coating treatment suppresses root rot diseases of alfalfa warrants further investigation. Zeolite that was cation exchanged with silver, copper, or zinc ions was shown to have broad antibacterial and antifungal activity, most likely due to release of these ions and uptake by microbes (7). The lack of inhibition of $S$. meliloti growth or interference with nodulation of roots by $S$. meliloti suggests that the mineral seed treatment does not have direct antimicrobial activity. However, a seed coating using zeolite that has been ion exchanged with copper may have greater activity against fungal and oomycete pathogens than natural zeolites. It is possible that the mineral seed coating alters the environment near the alfalfa seedling to inhibit plant infection. Natural zeolite, such as that used for the mineral coating, exchanges calcium, potassium, and sodium ions to the environment, which would result in localized alkalization of the spermosphere and rhizosphere. Alkalization of the area near the alfalfa seedling might inhibit germination of oospores or mycelial growth. In a previous study, germination of A. euteiches oospores did not occur at a pH greater than 5.1 (26). However, oospores of Phytophthora medicaginis germinated in root exudates with the $\mathrm{pH}$ adjusted from 3.5 to 10.5 (8). It is possible that, because of their high cation-exchange capacity, natural zeolites sequester cations from the soil or root exudates that trigger oospore germination. Previous experiments found that potassium permanganate $\left(\mathrm{KMnO}_{4}\right)$ induces germination of Pythium and Phytophthora oospores $(2,12)$ and that the cationic fraction of root exudates stimulates germination of $P$. medicaginis oospores (9). Removal of such cations may inhibit germination of oopores or reduce plant infection. It is also possible that alkalization of the rhizosphere induces changes in the amount or composition of plant root exudates. The composition of root exudate has been shown to influence oospore germination of A. euteiches (32). The inoculum used in our experiments consisted of oospores and mycelial fragments of $P$. medicaginis and A. euteiches. In both pathogens, oospores can germinate and infect plants directly or germinate to produce sporangia that release motile zoospores, which initiate infections. The flooded conditions of the assay would facilitate zoospore production and movement but it is not known whether oospores, zoospores, or mycelial fragments initiated infections in the assay. In the Pythium seed rot and damping-off assay, infection was likely initiated by mycelia because insufficient time had elapsed for oospores to form. Further experiments are needed to determine whether the mineral seed treatment interferes with oospore germination and mycelial growth.

A further possibility for the mechanism by which the mineral seed treatment suppresses disease is by triggering a disease defense response in the plants. Both biotic and abiotic inducers of localized and systemic disease resistance have been identified (36). Increased expression of defense response genes or increased resistance to foliar pathogens in plants from mineral-treated seed would be indicative of induced host resistance. The mineral seed-coating treatment may also trigger production of physical barriers to pathogen infection in the host plants.

An additional possible benefit of zeolite seed treatment is to facilitate slow release of plant nutrients. An increase in plant dry weight was observed in mock-inoculated plants from the mineral seed coating compared with the Apron XL and control coating treatments (Table 1). Possibly, this was due to uptake and slow release of the fertilizer that was applied to plants at 14 dap.

The zeolite mineral seed coating shows promise as a means to control important soilborne oomycete pathogens in situations in which an organic treatment is desired or other effective seed treatments are not available, or to reduce selection for conventional fungicide tolerance in pathogen populations. Zeolite is allowed under the National Organic Plan Rule 205.203(d) (2). Further testing is needed to assess effectiveness of the mineral seed coating against fungal pathogens of the alfalfa root rot complex, including $R$. solani and Fusarium spp., and to assess effectiveness of the seed treatment in field environments.

\section{Acknowledgments}

We thank M. Dornbusch for excellent technical assistance and J. Coulter and C. Sheaffer for providing field soil used in assays.

\section{Literature Cited}

1. Altier, N. A., and Thies, J. A. 1995. Identification of resistance to Pythium seedling diseases is alfalfa using a culture plate method. Plant Dis. 79:341-346

2. Ann, P. J., and Ko, W. H. 1988. Induction of oospore germination of Phytophthora parasitica. Phytopathology 78:335-338.

3. Bouton, J. 2007. The economic benefits of forage improvement in the United States. Euphytica 154:263-270.

4. Cummings, J. A., Miles, C. A., and du Toit, L. J. 2009. Greenhouse evaluation of seed and drench treatments for organic management of soilborne pathogens of spinach. Plant Dis. 93:1281-1292.

5. Davidse, L. C. 1981. Resistance to acylalanine fungicides in Phytophthora megasperma f. sp. medicaginis. Neth. J. Plant Pathol. 87:11-24.

6. Davis, A. S., Hill, J. D., Chase, C. A., Johanns, A. M., and Liebman, M. 2012. Increasing cropping system diversity balances productivity, profitability and environmental health. PLoS One 7:e47149.

7. Demirci, S., Ustaoglu, Z., Uilmazer, G. A., Sahin, F., and Baç, N. 2014. Antimicrobial properties of zeolite-X and zeolite-A ion-exchanged with 
silver, copper, and zinc against a broad range of microorganisms. Appl. Biochem. Biotechnol. 172:1652-1662.

8. Edmisten, K. L., Wolf, D. D., and Stromberg, E. L. 1988. Compatibility of metalaxyl with Rhizobium meliloti on alfalfa seed to control Pythium damping off. Crop Sci. 28:568-570.

9. El-Hamalawi, Z. A., and Irwin, D. C. 1986. Components in alfalfa root extract and root exudate that increase oospore germination of Phytophthora megasperma f. sp. medicaginis. Phytopathology 76:508-513.

10. Fidanza, M., and Settle, D. 2013. Evaluation of an inorganic soil amendment to reduce and manage fairy ring symptoms in turfgrass. Turfgrass Environ. Res. Online 12:6-8.

11. Froshelser, F. I. 1980. Conquering Phytophthora root rot with resistant alfalfa cultivars. Plant Dis. 64:909-912.

12. Guo, L. Y., and Ko, W. H. 1994. Factors affecting oospore germination of heterothallic Pythium splendens. Mycologia 86:777-780.

13. Hancock, J. G. 1983. Seedling diseases of alfalfa in California. Plant Dis. 67: 1203-1208.

14. Holub, E. B., and Grau, C. R. 1990. Productivity and survival of alfalfa ramets in soil naturally infested with Aphanomyces euteiches and Phytophthora megasperma. Can. J. Plant Pathol. 12:83-91.

15. Hunger, R. M., Hamm, P. B., Horner, C. E., and Hansen, E. M. 1982. Tolerance of Phytophthora megasperma isolates to metalaxyl. Plant Dis. 66: 645-649.

16. Hwang, S.-F., Wang, H., Gossen, B. D., Turnbull, G. D., Howard, R. J., and Strelkov, S. E. 2006. Effect of seed treatments and root pathogens on seedling establishment and yield of alfalfa, birdsfoot trefoil and sweetclover. Plant Pathol. J. 5:322-328.

17. Karlen, D. L., Varvel, G. E., Bullock, D. G., and Cruse, R. M. 1994. Crop rotations for the 21st century. Adv. Agron. 53:1-45.

18. Kazmar, E. R., Goodman, R. M., Grau, C. R., Johnson, D. W., Nordheim, E. V., Undersander, D. J., and Handelsman, J. 2000. Regression analyses for evaluating the influence of Bacillus cereus on alfalfa yield under variable disease intensity. Phytopathology 90:657-665.

19. Kyei-Boahen, S., Slinkard, A. E., and Walley, F. L. 2001. Rhizobial survival and nodulation of chickpea as influenced by fungicide seed treatment. Can. J. Microbiol. 47:585-589.

20. Malvick, D. K., and Grau, C. R. 2001. Characteristics and frequency of Aphanomyces euteiches races 1 and 2 associated with alfalfa in the Midwestern United States. Plant Dis. 85:740-744.

21. Malvick, D. K., Grünwald, N. J., and Dyer, A. T. 2009. Population structure, races, and host range of Aphanomyces euteiches from alfalfa production fields in the central USA. Eur. J. Plant Pathol. 123:171-182.

22. Margot, P. 1983. Control of seed-borne diseases with metalaxyl. Seed Sci. Technol. 11:921-933.

23. Ming, D. W., and Allen, E. R. 2001. Use of natural zeolites in agronomy, horticulture, and environmental soil remediation. Rev. Mineral. Geochem. 45:619-654.
24. Morton, H. V., and Urech, P. A. 1989. History of the development of resistance to phenylamide fungicides. Pages 59-60 in: Fungicide Resistance in North America. C. J. Delp, ed. The American Phytopathological Society, St. Paul, MN.

25. Munkvold, G. P., Carlton, W. M., Brummer, E. C., Meyer, J. R., Undersander, D. J., and Grau, C. R. 2001. Virulence of Aphanomyces euteiches isolates from Iowa and Wisconsin and benefits of resistance to A. euteiches in alfalfa cultivars. Plant Dis. 85:328-333.

26. Olofsson, J. 1968. Influence of hydrogen-ion concentration on germination of naturally produced oospores of Aphanomyces euteiches. Plant Dis. Rep. 52: 264-267.

27. Putnam, D., Russelle, M., Orloff, S., Kuhn, J., Fitzhugh, L., Gofrey, L., Kiess, A., and Long, R.2001. Alfalfa, wildlife and the environment: The importance and benefits of alfalfa in the 21st century. Online publication. California Alfalfa and Forage Association. http://alfalfa.ucdavis.edu/-files/pdf/Alf_Wild_Env_ BrochureFINAL.pdf

28. Ramos, M. L. G., and Ribeiro, W. Q., Jr. 1993. Effect of fungicides on survival of Rhizobium on seeds and the nodulation of bean (Phaseolus vulgaris L.). Plant Soil 152:145-150.

29. Revellin, C., Leterme, P., and Catroux, G. 1993. Effect of some fungicide seed treatments on the survival of Bradyrhizobium japonicum and on the nodulation and yield of soybean [Glycine $\max (\mathrm{L}$.) Merr.]. Biol. Fertil. Soils 16:211-214.

30. Rhodes, L. H., and Myers, D. K. 1989. Effect of seed treatment with metalaxyl or pyroxyfur on damping-off of alfalfa caused by Phytophthora megasperma f. sp. medicaginis. Crop Prot. 8:369-372.

31. Schmitthenner, A. F. 1964. Prevalence and virulence of Phytophthora, Aphanomyces, Pythium, Rhizoctonia, and Fusarium isolated from diseased alfalfa seedlings. Phytopathology 54:1012-1018.

32. Shang, H., Grau, C. R., and Peters, R. D. 2000. Oospore germination of Aphanomyces euteiches in root exudates and on the rhizoplanes of crop plants. Plant Dis. 84:994-998.

33. Vandemark, G. J., and Barker, B. M. 2003. Quantifying Phytophthora medicaginis in susceptible and resistant alfalfa with a real-time fluorescent PCR assay. J. Phytopathol. 151:577-583.

34. Vandemark, G. J., Barker, B. M., and Gritsenko, M. A. 2002. Quantifying Aphanomyces euteiches in alfalfa with a fluorescent polymerase chain reaction assay. Phytopathology 92:265-272.

35. Vincelli, P. 1992. Potential for seedling disease of alfalfa caused by Aphanomyces euteiches in Kentucky soil. Plant Dis. 76:622-626.

36. Walters, D. R., Ratsep, J., and Havis, N. D. 2013. Controlling crop diseases using induced resistance: challenges for the future. J. Exp. Bot. 64:1263-1280.

37. Wiersma, D. W., Grau, C. R., and Undersander, D. J. 1995. Alfalfa cultivar performance with differing levels of resistance to Phytophthora and Aphanomyces root rots. J. Prod. Agric. 8:259-264.

38. Yost, M. A., Coulter, J. A., and Russelle, M. P. 2013. First-year corn after alfalfa showed no response to fertilizer nitrogen under no-tillage. Agron. J. 105:208-214. 